\title{
Porous $\mathrm{Y}$ and $\mathrm{Cr}$-doped $\mathrm{SrTiO}_{3}$ materials-electrical and redox properties
}

\author{
Agnieszka Łącz ${ }^{1} \cdot$ Ewa Drożdż ${ }^{1}$ (1)
}

Received: 5 April 2019 /Revised: 19 August 2019 / Accepted: 29 August 2019 / Published online: 16 September 2019

(C) The Author(s) 2019

\begin{abstract}
Highly porous materials in the $\mathrm{Sr}_{0.96} \mathrm{Y}_{0.04} \mathrm{Ti}_{1-\mathrm{x}} \mathrm{Cr}_{\mathrm{x}} \mathrm{O}_{3}$ system (where $x=0,2,4,8$ mol.\%) were obtained by wet synthesis method. The structural and electrical properties of these materials were determined together with the ability to participate in oxidation/ reduction reactions, since yttrium is responsible for high electrical conductivity in reducing atmosphere and chromium is a factor affecting the catalytic properties. For the material with the highest assumed amount of chromium, the small content of an additional phase $\left(\mathrm{Cr}_{2} \mathrm{O}_{3}\right)$ was observed. $\mathrm{SrTiO}_{3}$ lattice parameters together with the results of temperature-programmed reduction (TPR) and temperature-programmed oxidation (TPOx) tests and Seebeck coefficient measurements allowed to determine the oxidation states of chromium in the received materials. It was shown that introduction of Y into strontium sublattice stabilises the strontium titanate structure and affects the oxidation state of chromium incorporated into the titanium sublattice. The defect structure in $\mathrm{Sr}_{0.96} \mathrm{Y}_{0.04} \mathrm{Ti}_{1-\mathrm{x}} \mathrm{Cr}_{\mathrm{x}} \mathrm{O}_{3}$ system is a complex problem, since yttrium is a donor type dopant and chromium due to the possible +3 and +6 oxidation states can be considered both acceptor and donor type one. Thus, a change in the conduction mechanism with the chromium content was observed in both oxidising and reducing atmosphere.
\end{abstract}

Keywords $\mathrm{Y}$ and $\mathrm{Cr}$-doped $\mathrm{SrTiO}_{3} \cdot$ Electrical conductivity $\cdot \mathrm{MIEC} \cdot$ Catalytic properties

\section{Introduction}

Perovskite systems are considered an alternative group of materials for nickel cermet (Ni/YSZ), in the context of an application in the electrochemical devices. Due to the high chemical stability $[1,2]$ and the possibility of reaching, after appropriate doping, high electron conductivity, one of the most promising is the system based on the strontium titanate. $\mathrm{SrTiO}_{3}$ is a dielectric, but one of the advantages of $\mathrm{ABO}_{3}$ perovskite structure is the possibility of relatively easy introduction of acceptor or donor dopants. Their incorporation into strontium (A position) and/or titanium (B position) sublattice leads to the modification of an electronic structure and consequently - the electrical properties of materials [3-5]. The donor doping, both in strontium (with lanthanum or yttrium) and titanium (with niobium or manganese) sublattice,

Ewa Drożdż

edrozdz@agh.edu.pl

1 Faculty of Materials Science and Ceramics, AGH University of Science and Technology, al. Mickiewicza 30,

30-059 Krakow, Poland results in an increase of the conductivity of materials working in a hydrogen atmosphere [6-13]. Yttrium and lanthanum are the most common donor dopants for the strontium sublattice, while niobium is often used for the titanium one. Moreover, it should be noted that $\mathrm{SrTiO}_{3}$ doped with yttrium, in comparison with the materials doped with the other mentioned elements, shows high chemical stability in the presence of water vapour and carbon dioxide [1].

One of the most perspective and the most expected application of $\mathrm{SrTiO}_{3}$-based materials is their adoption as an anode material in SOFC (solid oxide fuel cell) technology. However, the anode material should exhibit not only a high electrical conductivity but also a high catalytic activity in the fuel (hydrogen or hydrocarbon) oxidation reaction, which is not observed in the materials based on $\mathrm{SrTiO}_{3}$. Our recent research indicates that promising, catalytic properties can be expected for $\mathrm{SrTiO}_{3}$ doped with chromium [14]. Introduction of chromium, which can take various oxidation states depending on the atmosphere, suggests that $\mathrm{Cr}$-doped $\mathrm{SrTiO}_{3}$ system will exhibit catalytic activity in redox reactions and thus may be a potential catalyst for reforming reactions. On the other hand, concerning the electrical properties of the $\mathrm{Cr}-\mathrm{SrTiO}_{3}$ system, chromium is a donor dopant in air atmosphere, while in 
reducing one it can be treated as an acceptor one [14-16]. Moreover, the results of the temperature-programmed reduction and oxidation (TPR/TPOx) confirmed that chromium incorporated in the titanium sublattice in $\mathrm{SrTiO}_{3}$ structure changes the oxidation state with the atmosphere, without creating the additional phases [14]. The literature concerning an incorporation of $\mathrm{Cr}$ into $\mathrm{SrTiO}_{3}$ structure is usually focused on the photocatalytic properties of this system [17-19], while the electrical and catalytic properties are not discussed. Together with the effects of the previous study stating the high electrical conductivity of Y-doped $\mathrm{SrTiO}_{3}$ in reducing atmosphere $[4,9$, 10], it became an impulse to the synthesis of the doubledoped, simultaneously with yttrium and chromium, $\mathrm{SrTiO}_{3}$ where chromium is a factor which can determine the catalytic activity of the entire system. The characterisation of these materials was undertaken to evaluate their potential value as anode materials for SOFC cells, since the simultaneous doping of $\mathrm{SrTiO}_{3}$ structure with $\mathrm{Y}$ and $\mathrm{Cr}$ was not previously discussed in the literature.

The performance of the anodic reaction is affected by the porosity and the grain size of the material; thus, the proper selection of the synthesis method is one of the crucial factors. The wet synthesis method applied in this work allows to receive the nanocrystalline materials with high specific surface area, which affects both the grain size and the active surface of the final electrode in oxidation reaction as well as fast recovery of the system to equilibrium in high temperature conditions [20]. Also, this type of the microstructure is able to provide the appropriate three-phase boundary (TPB) which is one of the main factors determining the rate of the electrode reaction processes on the anode $[3,21]$.

\section{Experimental}

\section{Material preparation}

Wet synthesis method was applied to obtain a series of yttrium and chromium-doped strontium titanate materials with high porosity. At first, $\mathrm{Ti}(\mathrm{O}-\mathrm{iPr})_{4}$ - titanium(IV) isopropoxidewas mixed with citric acid (1:2 molar ratio) in anhydrous ethanol; afterward, the appropriate amount of water solutions of strontium nitrate $\left(1.05 \mathrm{~mol} / \mathrm{dm}^{3}\right)$, yttrium nitrate $(0.80 \mathrm{~mol} /$ $\left.\mathrm{dm}^{3}\right)$ and chromium nitrate $\left(0.95 \mathrm{~mol} / \mathrm{dm}^{3}\right)$ was added. The received solutions were dried on magnetic stirrer to form a gel. The resultant mixtures were heated at $200{ }^{\circ} \mathrm{C}$ (for densification) and calcined at $900{ }^{\circ} \mathrm{C}\left(3 \mathrm{~h}, 1 \mathrm{deg} \min ^{-1}\right.$ heating rate). The received powders were formed into pellets (under pressure $\left.5 \times 10^{5} \mathrm{~Pa}\right)$ and sintered at $1200{ }^{\circ} \mathrm{C}\left(3 \mathrm{~h}, 5 \mathrm{deg} \mathrm{min}^{-1}\right.$ heating rate). As a result, a series of samples with the general formula $\mathrm{Sr}_{0.96} \mathrm{Y}_{0.04} \mathrm{Ti}_{1-\mathrm{x}} \mathrm{Cr}_{\mathrm{x}} \mathrm{O}_{3}$ where $x=0,2,4,8$ mol. $\%$ was obtained. Individual samples in the further part of the manuscript were assigned the following labels: STO,
STO $4 \mathrm{Y} \_2 \mathrm{Cr}$, STO $4 \mathrm{Y} \_4 \mathrm{Cr}$ and STO $4 \mathrm{Y} \_8 \mathrm{Cr}$ for $\mathrm{SrTiO}_{3}$, $\mathrm{Sr}_{0.96} \mathrm{Y}_{0.04} \mathrm{Ti}_{0.98} \mathrm{Cr}_{0.02} \mathrm{O}_{3}, \mathrm{Sr}_{0.96} \mathrm{Y}_{0.04} \mathrm{Ti}_{0.96} \mathrm{Cr}_{0.04} \mathrm{O}_{3}$ and $\mathrm{Sr}_{0.96} \mathrm{Y}_{0.04} \mathrm{Ti}_{0.92} \mathrm{Cr}_{0.08} \mathrm{O}_{3}$, respectively.

\section{Methods and apparatus}

X-ray diffraction measurements performed on Philips X'Pert Pro diffractometer with monochromatized $\mathrm{Cu}-\mathrm{K} \alpha$ radiation were used to determinate the phase composition of synthesised materials and unit cell parameters. Scanning electron microscopy (SEM) (Nova NanoSEM 200 FEI, Oxford Instruments) coupled with X-ray energy dispersive spectroscopy (EDAX company apparatus) was carried out for microstructure observation and chemical composition analysis.

To evaluate the ability of the materials to participate in redox reactions, temperature-programmed reduction (TPR) and temperature-programmed oxidation (TPOx) measurements were performed by ChemiSorb 2750 apparatus (produced by Micromeritics). The oxidation and reduction processes were carried out in the flow of $5 \% \mathrm{O}_{2} / \mathrm{Ar}$ in $5 \% \mathrm{H}_{2} /$ Ar mixtures, respectively. The samples with the mass around $0.350 \mathrm{~g}$ were placed in quartz reactor and heated with the rate of $10 \mathrm{deg} \mathrm{min}^{-1}$ up to $900{ }^{\circ} \mathrm{C}$.

Electrochemical impedance spectroscopy (EIS) (Solartron FRA 1260 with dielectric interface 1294) was used for determination of the electrical properties. The sintered pellets in the form of discs $-10 \mathrm{~mm}$ in diameter and $2 \mathrm{~mm}$ of thicknesswere used for this measurements. The platinum paste (Heraeus Pt LP 11-4493 paste) was applied on both sides of the pellets and next fired at $800{ }^{\circ} \mathrm{C}$ for $20 \mathrm{~min}$ to form the porous electrodes. EIS measurements were performed in the range of temperature $400-700{ }^{\circ} \mathrm{C}$ in oxidising (synthetic air) and reducing $\left(10 \% \mathrm{H}_{2}\right.$ in $\left.\mathrm{Ar}\right)$ atmospheres. Before each measurement, the samples were stabilised at given temperature for $30 \mathrm{~min}$. The Seebeck coefficient measurements (Fine Instruments apparatus supported on Keysight Technology multimeter) were performed to determine the type of the majority charge carriers in the synthesised materials under air as a function of temperature $\left(300-700{ }^{\circ} \mathrm{C}\right)$.

\section{Results and discussion}

Wet synthesis method allowed obtaining materials with high porosity. Figure 1 shows the microstructure of powder after calcination and cross-section of sintered pellet for one of the compositions-STO 4Y 2Cr. It can be noticed that the sintered materials consist of aggregates with 100-200-nm size and exhibit high porosity. The total porosities for pellets sintered at $1200{ }^{\circ} \mathrm{C}$ were about $50 \pm 2$ vol.\%, without any trends connected with the amount of dopants. These values were estimated on the basis of samples' mass and geometry. 
Fig. 1 SEM microphotographs of calcinated powder and pellets fracture of sintered material together with EDS analysis results calcination $-900^{\circ} \mathrm{C} / 3 \mathrm{~h}$

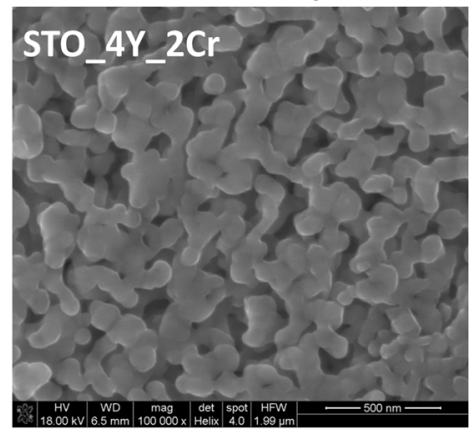

sintering $-1200^{\circ} \mathrm{C} / 3 \mathrm{~h}$

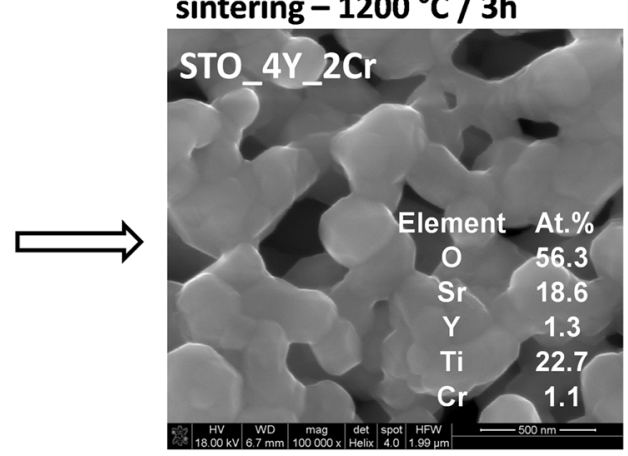

The analysis of the XRD measurements results (Fig. 2) showed the presence of cubic $\mathrm{SrTiO}_{3}$ phase (Pm-3m space group, ICSD 98-006-5089) for the undoped material and the materials doped with 4 mol.\% of yttrium and 2 and 4 mol.\% of chromium. However due to the presence of a small peak at $2 \theta$ around $52^{\circ}$ (for STO_4Y_2Cr sample), the existence of small amount of $\mathrm{Y}_{2} \mathrm{Ti}_{2} \mathrm{O}_{7}$ phase can be suspected; still no other peaks characteristic for this phase can be seen. For the material with the highest content of chromium admixture (8 mol.\%), the additional phase - chromium(III) oxide (rhombohedral $\mathrm{Cr}_{2} \mathrm{O}_{3}$, R-3c space group, ICSD 01-070-3766) - appeared in the amount of $1.2 \mathrm{wt} . \%$.

In Table 1 the strontium titanate lattice parameters, determined by Rietveld refinement method, for synthesised undoped $\mathrm{SrTiO}_{3}$ and $\mathrm{SrTiO}_{3}$ doped with $\mathrm{Y}$ and $\mathrm{Cr}$ were collected.

Generally, the $a$ parameter decreases with an increase of chromium amount introduced into the $\mathrm{SrTiO}_{3}$ structure. This effect should be discussed concerning the values of ionic radii of incorporated dopants-yttrium and chromium. In $\mathrm{SrTiO}_{3}$ structure, strontium and titanium occur in 12-fold and 6-fold coordination, respectively. Thus, the ionic radius of $\mathrm{Sr}^{2+}$ is

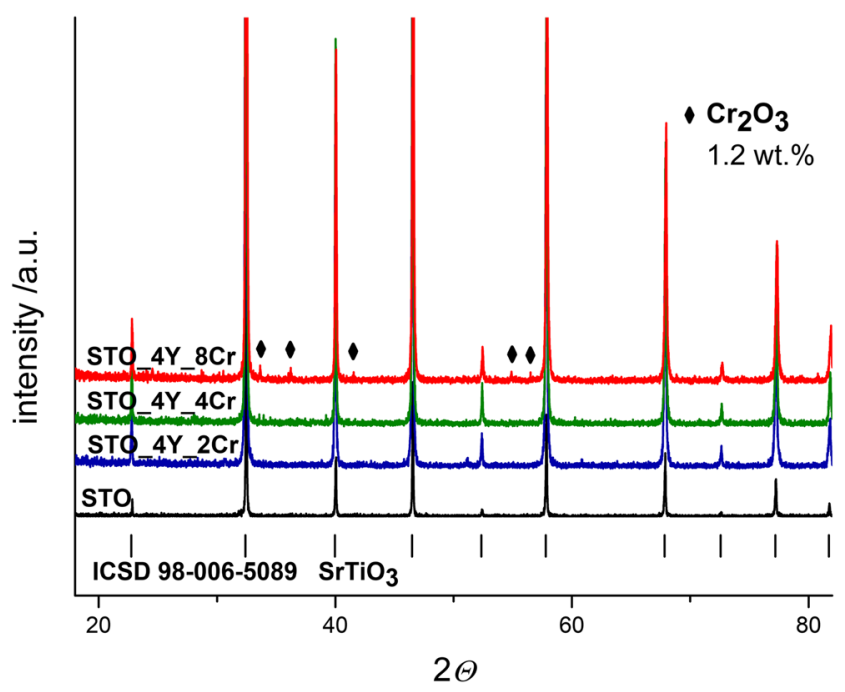

Fig. 2 Diffraction patterns of undoped and doped $\mathrm{SrTiO}_{3}$ samples sintered at $1200{ }^{\circ} \mathrm{C}$
$1.58 \AA$ and the ionic radius of $\mathrm{Ti}^{4+}$ is $0.745 \AA$ [22]. As was previously reported, doping of $\mathrm{SrTiO}_{3}$ with yttrium results in its incorporation into the strontium sublattice and the reduction of the strontium titanate lattice parameter, as yttrium ionic radius is around $1.3 \AA$ (for $\mathrm{CN}=12$ ). It is also known that chromium incorporated into titanium sublattice takes both +3 and +6 oxidation state [14]. Considering the ionic radii of $\mathrm{Cr}^{3+}$ $(0.755 \AA), \mathrm{Cr}^{6+}(0.580 \AA)$ and $\mathrm{Ti}^{4+}(0.745 \AA)$, it can be concluded that doping with chromium(VI) results in a decrease of the lattice parameter, while doping with chromium(III) leads to an increase of the lattice parameter. As the incorporation of yttrium into the strontium sublattice has a significant influence on the decrease of the $\mathrm{SrTiO}_{3}$ lattice parameter, thus to observe the chromium effect on the $a$ value, the reference material- $\mathrm{SrTiO}_{3}$ doped with 4 mol.\% of yttrium (STO_4Y) — was also synthesised and investigated. As was expected, a reduction of the lattice parameter after the introduction of yttrium into the tausonite structure is clearly seen (Table 1). Furthermore, an introduction of chromium also affects the value of the lattice parameter-for material with smallest amount of chromium (STO_4Y_2Cr), the slight increase of $a$ value is observed in comparison with STO_4Y sample, where only yttrium doping was applied. This result suggests the incorporation of chromium at +3 oxidation state not just only at +6 , as one might expect, considering that the synthesis of the material was carried out under oxidative conditions. However, the presence of $\mathrm{Cr}^{6+}$ in the structure cannot be excluded; even more it could be suspected since the increase of the lattice parameter is not significant. It stays in agreement with previously reported results of XPS measurements which confirmed that in tausonite structure chromium takes +3 and +6 oxidation state [14]. Further increase of the chromium amount (STO_4Y_4Cr, STO_4Y_8Cr) leads to a gradual decrease of the lattice parameter. Thus, the incorporation of chromium, probably on both possible oxidation states, can be observed. The changes in the $\mathrm{Cr}^{3+} / \mathrm{Cr}^{6+}$ ratio with an increase of the chromium amount can be postulated, especially that the change in the samples' colour was observed. The colour of STO_4Y_2Cr and STO_4Y_4Cr samples were green-light beige and green-beige, respectively. It suggests the dominant presence of $\mathrm{Cr}^{3+}$ in the structures. The last 
Table $1 \quad \mathrm{SrTiO}_{3}$ lattice parameter for synthesised materials

\begin{tabular}{|c|c|c|c|c|c|}
\hline Sample & STO & STO_4Y & STO_4Y_2Cr & STO_4Y_4Cr & STO_4Y_8Cr \\
\hline $\begin{array}{l}\text { Lattice parameter } \\
a[\AA]\end{array}$ & $3.9064 \pm 0.0003$ & $3.9021 \pm 0.0002$ & $3.9027 \pm 0.0013$ & $3.9018 \pm 0.0001$ & $3.9006 \pm 0.0002$ \\
\hline
\end{tabular}

sample STO 4Y 8Cr was burgundy-beige, what clearly suggests the large amount of $\mathrm{Cr}^{6+}$. As was reported, based on the XRD measurement results, STO_4Y_8Cr sample was twophase materials with $1.2 \mathrm{wt} . \%$ of $\mathrm{Cr}_{2} \overline{\mathrm{O}}_{3}$; thus, the amount of chromium incorporated into the Y-doped $\mathrm{SrTiO}_{3}$ is smaller than the assumed $8 \mathrm{~mol} . \%$. Based on the amount of $\mathrm{Cr}_{2} \mathrm{O}_{3}$ determined by the Rietveld refinement method and stoichiometric calculations, the number of chromium moles, which were incorporated in the perovskite structure, was estimated. It was concluded that $\mathrm{SrTiO}_{3}$ structure doped with 4 mol.\% of yttrium can accept 5 mol.\% of chromium, less than assumed 8 mol.\% but more than in the case of the remaining samplesSTO_4Y_2Cr and STO_4Y_4Cr. Also, the change in the samples colour suggests that, with the increase of the content of incorporated chromium, the amount of $\mathrm{Cr}^{6+}$ in the perovskite structure increases.

The oxidation-reduction properties of $\mathrm{Y}$ and $\mathrm{Cr}$-doped $\mathrm{SrTiO}_{3}$ and the possibility of reduction of chromium incorporated into the perovskite structure were analysed by the series of TPR and TPOx measurements with the procedure presented in Fig. 3.

Analysis of the reduction capabilities of doped $\mathrm{SrTiO}_{3}$ systems was performed based on the second reduction cycle data (II TPR). It was considered that the first reduction cycle (I TPR) may not be reliable due to the different residence time of the materials after the synthesis and to eliminate the effect of some additional factors the profiles of the second reduction cycle (II TPR) were analysed. Thus, the first reduction and subsequent oxidation (I TPOx) were used to normalize the conditions for all materials.

Figure 4 presents the TPR profiles for all double (Y and Cr)-doped $\mathrm{SrTiO}_{3}$ materials; also, the data for single-doped $\mathrm{SrTiO}_{3}$ with 4 mol.\% of yttrium (STO_4Y) and with 4 mol.\% of chromium (STO_4Cr) were added as the reference samples. In the case of Y-doped $\mathrm{SrTiO}_{3}$, only one small, broad peak in the temperature range $500-760^{\circ} \mathrm{C}$ is seen, indicating the small ability to reduction of the material. Considering the fact that yttrium does not change the oxidation state, the only reduction process that can occur in this system is the reduction of titanium $\left(\mathrm{Ti}^{4+} \rightarrow \mathrm{Ti}^{3+}\right)$ with simultaneous removal of oxygen from the perovskite structure. For $\mathrm{Cr}$-doped $\mathrm{SrTiO}_{3}$, there are two reduction effects - the first (narrow with high intensity) starts already around $300{ }^{\circ} \mathrm{C}$ and the second (slight, broad) appears in the temperature range above $500{ }^{\circ} \mathrm{C}$. Thus, the earlier corresponds to the reduction of chromium, while the latter describes the reduction of titanium.

TPR reduction profiles of single-phase chromium and yttrium-doped $\mathrm{SrTiO}_{3}\left(\mathrm{STO}_{-} 4 \mathrm{Y} \_2 \mathrm{Cr}\right.$ and $\mathrm{STO} 44 \mathrm{Y} \_4 \mathrm{Cr}$ ) show two effects: the first one starts at $380{ }^{\circ} \mathrm{C}$ and the second starts at about $500{ }^{\circ} \mathrm{C}$. Considering the reduction processes in $\mathrm{SrTiO}_{3}$ doped only with chromium or yttrium, it can be stated that in double-doped materials, the first effect corresponds to the reduction of chromium (VI) to a lower oxidation state, while the second effect illustrates the titanium reduction. The relatively small intensity of the first peaks clearly indicates the small amount of $\mathrm{Cr}^{6+}$ in both samples. Also, since the peak area is proportional to the $\mathrm{Cr}^{6+}$ content, the comparable amount of chromium on +6 oxidation state in STO_4Y_2 $\mathrm{Cr}$ and STO_4Y_4Crsamples can be implied. The comparison of TPR profiles for STO_4Cr and STO_4Y_4Cr indicates that introduction of yttrium dopant into strontium sublattice affects the incorporation of chromium into the titanium sublattice, since the smaller amount of chromium takes +6 oxidation state in the material doped with $\mathrm{Y}^{3+}$. Consequently, the $\mathrm{Cr}^{3+} / \mathrm{Cr}^{6+}$ ratio is significantly different for $\mathrm{STO}_{4} 4 \mathrm{Cr}$ and $\mathrm{STO} 44 \mathrm{Y} 4 \mathrm{Cr}$ sample. Thus, it can be postulated that introduction of donor dopant into the strontium sublattice forces the incorporation of chromium as an acceptor dopant (on the +3 oxidation state) to compensate the electronic defects generated by yttrium incorporation. The two-phase $\mathrm{Y}$ and $\mathrm{Cr}$-doped $\mathrm{SrTiO}_{3}$ sample (STO_4Y_8Cr) shows a completely different behaviour during the reduction process - one high intensity reduction peak starting at about $400{ }^{\circ} \mathrm{C}$ is clearly observed, while from 500 ${ }^{\circ} \mathrm{C}$ only slight increase in the background can be detected. It implies that the higher amount of $\mathrm{Cr}^{6+}$ is incorporated into the $\mathrm{SrTiO}_{3}$ structure in comparison with other $\mathrm{Y}$ and $\mathrm{Cr}$-doped materials. Thus, it can be postulated that after removing some amount of chromium as $\mathrm{Cr}_{2} \mathrm{O}_{3}$ from the structure, the +6 oxidation state for chromium is more privileged. The results of TPR measurements stay in agreement with the discussion
Fig. 3 The scheme of temperature-programed reduction/oxidation tests

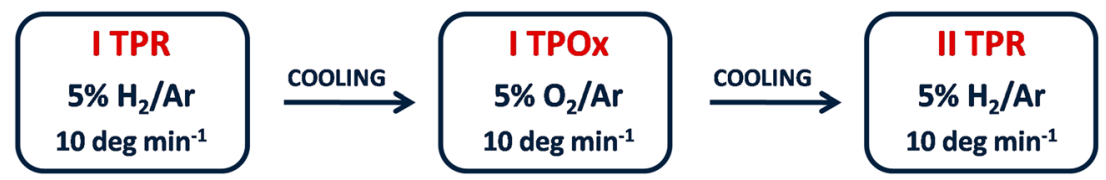




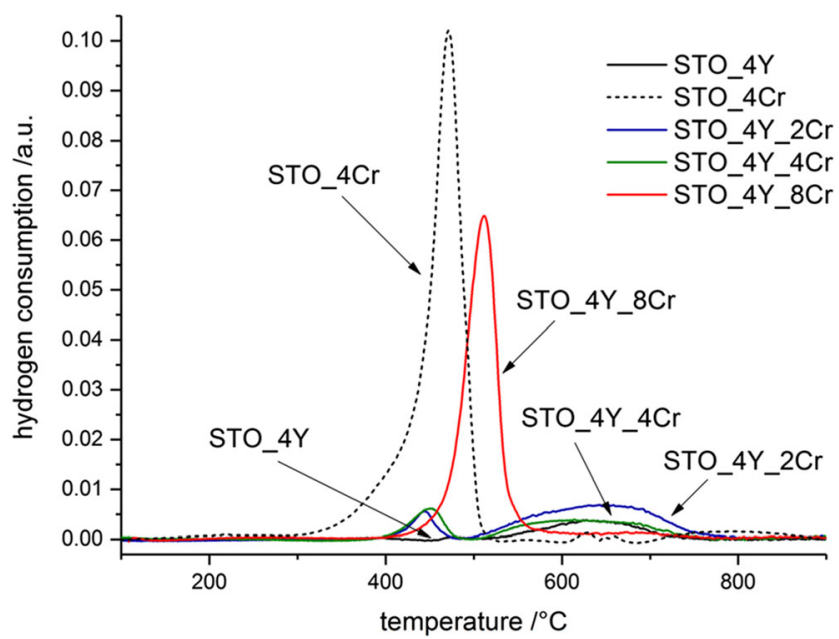

Fig. 4 II TPR profiles for $\mathrm{Y}$ and $\mathrm{Cr}$-doped $\mathrm{SrTiO}_{3}$ series

based on the samples colour, as samples with small amount of $\mathrm{Cr}^{6+}$ (STO_4Y_2Cr, STO_4Y_4Cr) were green-beige and sample with high content of chromium on +6 oxidation state (STO_4Y_8Cr) was burgundy-beige. It should also be noted that TPR studies allow explaining the origin of the colour of STO_4Y_8Cr material which could not be done on the basis of XRD research results. The presence of $\mathrm{Cr}_{2} \mathrm{O}_{3}$ in the STO_4Y_8Cr sample should lead to the green colour of the material. In fact, this colour was burgundy due to the significant content of $\mathrm{Cr}^{6+}$, which was confirmed by the TPR measurements. It should be noted that for all double ( $\mathrm{Y}$ and $\mathrm{Cr}$ )doped $\mathrm{SrTiO}_{3}$ materials, the effect related to chromium reduction is shifted toward higher temperatures compared with this effect for STO_4Cr material, which proves the stabilising effect of yttrium incorporated to the strontium titanate structure.

The Seebeck coefficient measurements carried out in air atmosphere were performed to define the type of majority charge carriers and to discuss the effect of chromium oxidation state on the materials' defect structure. The Seebeck coefficients as a function of temperature for $\mathrm{Y}$ and $\mathrm{Cr}$ double-doped $\mathrm{SrTiO}_{3}$, together with the data for undoped $\mathrm{SrTiO}_{3}$ and $\mathrm{SrTiO}_{3}$ doped with yttrium/chromium as the references are presented in Fig. 5. In undoped $\mathrm{SrTiO}_{3}$, hole carriers naturally occur [5, 23]; thus, the positive value of the Seebeck coefficient can be observed. Introduction of yttrium into $\mathrm{SrTiO}_{3}$ structure in strontium position results in the change of the Seebeck coefficient sign (Fig. 5); since $\mathrm{Y}^{3+}$ is considered the donor type dopant, its incorporation is connected with generation of electrons.

Effect of chromium doping on the Seebeck coefficient sign is more complex, while chromium incorporated into the titanium position can take both +3 and +6 oxidation state, thus can be treated simultaneously as the acceptor and the donor type dopant and the observed Seebeck coefficient sign is the result of defect balance in the structure. For STO_4Y_4Cr sample, the sign of Seebeck coefficient is positive; thus, the holes are the major charge carriers. Concerning that doping

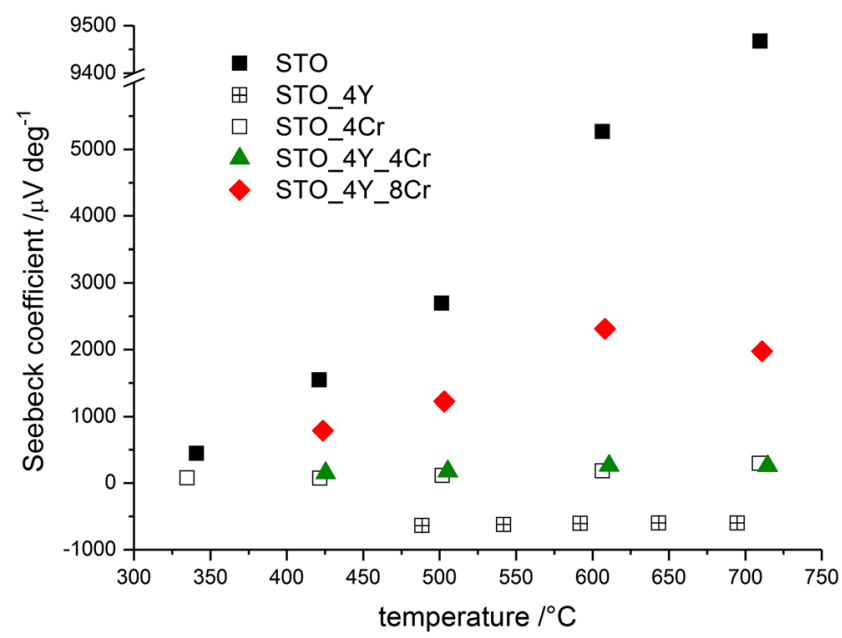

Fig. 5 Seebeck coefficient of undoped and doped $\mathrm{SrTiO}_{3}$ samples measured in synthetic air

with both $\mathrm{Y}^{3+}$ and $\mathrm{Cr}^{6+}$ leads to generation of electrons, thus, the content of the $\mathrm{Cr}^{3+}$ in the doped $\mathrm{SrTiO}_{3}$ structure must be relatively high, especially that electron-hole recombination is also highly probable. It stays in agreement with the TPR measurement results indicating that yttrium doping in the strontium position results with the change of $\mathrm{Cr}^{3+} / \mathrm{Cr}^{6+}$ ratio due to the increase of $\mathrm{Cr}^{3+}$ content. According to the TPR measurement results for two-phase $\mathrm{STO}_{-} 4 \mathrm{Y} \_8 \mathrm{Cr}$ sample, the significant increase of the $\mathrm{Cr}^{6+}$ content in the doped $\mathrm{SrTiO}_{3}$ structure was observed which should lead to generation of electrons. However, the sign of the Seebeck coefficient is still positive (Fig. 5). Thus, the effect of the presence of an additional phase $-\mathrm{Cr}_{2} \mathrm{O}_{3}-$ should be considered. According to the literature, chromium(III) oxide is a p-type conductor at temperatures below $1000{ }^{\circ} \mathrm{C}$ [24]. However, this is not the main reason of the change in the Seebeck coefficient sign, since the formation of other defects due to leaving chromium from the perovskite structure should also be considered. Thus, the sign of the Seebeck coefficient in the case of STO_4Y_8Cr sample is an effect of both the electrical properties of $\mathrm{Cr}_{2} \mathrm{O}_{3}$ and $\mathrm{SrTiO}_{3}$ defect structure. This problem will be discussed in more detail in the section on the conductivity of the materials.

The electrical properties of $\mathrm{Cr}$ and $\mathrm{Y}$-doped $\mathrm{SrTiO}_{3}$ were characterised for oxidising (synthetic air) and reducing (10\% $\mathrm{H}_{2} / \mathrm{Ar}$ ) atmospheres in the temperature range $400-700{ }^{\circ} \mathrm{C}$ by means of electrochemical impedance spectroscopy. The representative EIS spectra for measurement performed at $300{ }^{\circ} \mathrm{C}$ in air as a function of materials' composition and the results for STO_4Y_8Cr sample in reducing atmosphere as a function of temperature are presented in Fig. $6 \mathrm{a}$ and b, respectively. The Nyquist plots for all samples in both atmospheres reveal one semicircle; thus, the ionic type of conductivity can be expected in the synthesised materials. The total conductivities were calculated based on the resistance obtained from the Bode plots and the samples' geometry. The dependence of total conductivity on temperature in Arrhenius coordinates 



Fig. 6 The representative EIS spectra for $\mathrm{SrTiO}_{3}$-based materials. The measurements were performed in synthetic air (a) and 10\% H2 in $\mathrm{Ar}(\mathbf{b})$

for air and $10 \% \mathrm{H}_{2}$ in Ar is presented in Fig. 7a and b, respectively. Based on the presented results, the activation energies of total conductivity were calculated and collected at Table 2 for both oxidising and reducing atmospheres.

It should be underlined that the defect structure in $\mathrm{Y}$ and $\mathrm{Cr}$-doped $\mathrm{SrTiO}_{3}$ is a complex issue, since yttrium is a donor dopant, while chromium, due to the different possible oxidation states $(+3$ and +6$)$, can be treated as an acceptor and donor type dopant, respectively. Additionally, as was previously reported, chromium takes both oxidation states while it is introduced into $\mathrm{SrTiO}_{3}$ structure and the $\mathrm{Cr}^{3+} / \mathrm{Cr}^{6+}$ ratio varies with the dopant amount [14]. Incorporation of yttrium and chromium into strontium titanate structure can be written as follows:

$$
\begin{aligned}
& \mathrm{Y}_{2} \mathrm{O}_{3} \stackrel{\mathrm{SrTiO}_{3}}{\longrightarrow} 2 \mathrm{Y}_{\mathrm{Sr}}^{\bullet}+2 \mathrm{e}^{\prime}+3 \mathrm{O}_{\mathrm{o}}^{\mathrm{x}} \\
& \mathrm{Cr}_{2} \mathrm{O}_{3} \stackrel{\mathrm{SrTiO}_{3}}{\longrightarrow} 2 \mathrm{Cr}_{\mathrm{Ti}}^{\prime}+2 \mathrm{~h}^{\bullet}+3 \mathrm{O}_{\mathrm{o}}^{\mathrm{x}} \\
& \mathrm{CrO}_{3} \stackrel{\mathrm{SrTiO}_{3}}{\longrightarrow} \mathrm{Cr}_{\mathrm{Ti}}^{\bullet}+2 \mathrm{e}^{\prime}+3 \mathrm{O}_{\mathrm{o}}^{\mathrm{x}}
\end{aligned}
$$

However, recombination of electron-hole (Eq. 4) pairs is also highly possible.

$\mathrm{h}^{\bullet}+\mathrm{e}^{\prime}=$ nil

Concerning the ionic type of conductivity observed in yttrium and chromium-doped $\mathrm{SrTiO}_{3}$ materials and the high hole defect concentration as an effect of acceptor doping, the following process of oxygen vacancy formation should also be considered:

$\mathrm{O}_{\mathrm{O}}^{\mathrm{x}}+2 \mathrm{~h}^{\cdot} \rightarrow \frac{1}{2} \mathrm{O}_{2(\mathrm{~g})}+\mathrm{V}_{\mathrm{O}}^{*}$

In the $\mathrm{Y}$-doped $\mathrm{SrTiO}_{3}$ materials, the oxide-ion conductivity is dominant at air atmosphere, since the electrons introduced into the structure as the result of donor doping create the small polarons located at two titanium ions close to the yttrium dopant [25]. Generally, chromium addition leads to an increase of the conductivity in comparison with materials doped only with yttrium (Fig. 7a). However, this dependency for single-phase $\mathrm{Y}$ and $\mathrm{Cr}$-doped materials (STO_4Y_2Cr, STO_4Y_4Cr) is in accordance only for temperature below $600{ }^{\circ} \mathrm{C}$. For higher temperatures, the differences between the conductivity of single-doped and double-doped $\mathrm{SrTiO}_{3}$ are less significant. Also, for single-phase materials, the decrease of activation energy of conductivity is observed with an increase of the incorporated chromium amount (Table 2). It must
Fig. 7 Temperature dependence of the total conductivity of samples measured in synthetic air (a) and $10 \% \mathrm{H}_{2}$ in $\mathrm{Ar}(\mathbf{b})$

Table 2 Activation energy of total conductivity for doped$\mathrm{SrTiO}_{3}$ materials

\begin{tabular}{lllll}
\hline Atmosphere & \multicolumn{4}{l}{ Activation energy $(\mathrm{eV})$} \\
\cline { 2 - 5 } & STO_4Y & STO_4Y_2Cr & STO_4Y_4Cr & STO_4Y_8Cr \\
\hline Air & $1.47 \pm 0.04$ & $0.94 \pm 0.04$ & $0.56 \pm 0.01$ & $0.34 \pm 0.01$ \\
$10 \% \mathrm{H}_{2}$ in $\mathrm{Ar}$ & $0.64 \pm 0.01$ & $0.69 \pm 0.01$ & $0.73 \pm 0.02$ & $1.05 \pm 0.02$ \\
\hline
\end{tabular}

be mentioned that an activation energy of hole conductivity in the perovskite structure materials is about $0.2-0.4 \mathrm{eV}$ [26], while the activation energy for oxygen conductivity is close to $0.9-1.2 \mathrm{eV}[27,28]$. Thus, the change in the conduction mechanism can be postulated. As was previously discussed in the double-doped $\mathrm{SrTiO}_{3}$, yttrium forces the incorporation of chromium on +3 oxidation state; thus, an increase in the hole concentration can be expected. It should be followed by an increase of the hole conductivity and change the conduction mechanism to mixed type (ionic and hole) conductivity. Thus, the decrease of the activation energy of total conductivity can be observed for $\mathrm{Y}$ and $\mathrm{Cr}$-doped $\mathrm{SrTiO}_{3}$ materials in comparison with Y-doped one (Table 2). According to the TPR profiles, the amount of $\mathrm{Cr}^{6+}$ is comparable in STO_4Y $2 \mathrm{Cr}$ and STO_4Y_4Cr samples. It should result in an increase of $\mathrm{Cr}^{3+}$ content and hole concentration in STO_4Y_4Cr in comparison with STO_4Y_2Cr. It stays in agreement with the conductivity measurement results, as the total conductivity of STO_4Y_4Cr sample is higher. Also, the activation energy of conductivity of STO_4Y_4Cr samples decreases, due to the higher share of the hole conductivity (Table 2). For twophase STO_4Y_8Cr, the significant increase of conductivity is observed. The influence of an additional $\mathrm{Cr}_{2} \mathrm{O}_{3}$ phase on the value of conductivity should be considered, since chromium(III) oxide is a p-type conductor [21]. Thus, an increase of the total conductivity could be expected. However, due to the relatively small $\mathrm{Cr}_{2} \mathrm{O}_{3}$ content $(1.2 \mathrm{wt}$. $\%$ ), the percolation threshold has probably not been exceeded. Thus, another explanation of the conductivity increases should be considered. According to the TPR studies, in STO_4Y_8Cr sample, the relatively high content of $\mathrm{Cr}^{6+}$ was observed. It leads to a high electron concentration (Eq. 3) and an increase of the conductivity as well as a decrease of its activation energy due to an increase of the electron conductivity contribution to the total conductivity. However, it must also be mentioned that the Seebeck coefficient sign for this materials is positive what suggests hole conductivity of the system. Considering this effect, it should be taken into account that the formation of $\mathrm{Cr}_{2} \mathrm{O}_{3}$ is followed by the change of the $\mathrm{SrTiO}_{3}$ defect structure, most probably the creation of titanium vacancies and holes that arise in connection with the necessity to lattice charge compensation for the negative charge of titanium vacancies. However, the other effects cannot be excluded-the creation of oxide ion vacancies and substitution of strontium into titanium position [29, 30]. Thus, resultant effect affects the sign of Seebeck coefficient and leads to an increase of conductivity of the system compared with the samples with a lower content of chromium.

In order to determine the electrical properties of the tested systems in the potential working conditions of anode in SOFC technology, conductivity tests in $10 \% \mathrm{H}_{2}$ in Ar mixture were carried out (Fig. 7b). Generally, an introduction of acceptor dopant into the $\mathrm{SrTiO}_{3}$-based systems results in a decrease of the conductivity in the reducing atmosphere, due to the compensation of electron-hole pairs. The holes created as the result of acceptor doping can recombined with electron generated by two effects - the reducing nature of hydrogen atmosphere and the release of oxygen from the perovskite structure. The second effect leads to an increase of the share of ionic conductivity. However, introduction of donor dopant (yttrium) is also one of the main sources of electrons. Thus, the relatively high conductivity of STO_4Y (Fig. 7b) in the reducing atmosphere is a result of high electron and oxygen vacancy content. Additionally, the mixed ionic-electron type of conductivity can be postulated. It also stays in agreements with the value of activation energy (Table 2 ). Introduction of chromium on +3 oxidation state results in an increase of the hole content and due to their recombination with electrons the decrease of the charge carriers leading to the decrease of the total conductivity (Fig. 7b). The activation energies of conductivity for singlephase materials (STO_4Y, STO_4Y_2Cr, STO_4Y_4Cr) do not show the significant differences; thus, the mechanism of conductivity is rather not affected by the chromium doping. It must also be mentioned that reduction of chromium incorporated into the structure on +6 oxidation state to $\mathrm{Cr}^{3+}$ in hydrogen containing atmosphere is also highly probable. For the material with the highest chromium content ( $\mathrm{STO} 4 \mathrm{Y} \_8 \mathrm{Cr}$ ), the influence of the presence of a second phase is observed in a value of conductivity and its activation energy. As was previously mentioned due to the relative low $\mathrm{Cr}_{2} \mathrm{O}_{3}$ contents, the percolation threshold is not exceeded; thus, the additional phase can have a blocking effect on the conductivity at reducing atmosphere and the increase of the activation energy of conductivity is observed (Table 2). Moreover, the second effect should also be considered-according to the literature hydrogen can dissolve in the $\mathrm{Cr}_{2} \mathrm{O}_{3}$ structure leading to the change of the defect balance and decrease of the material conductivity [25]. 


\section{Conclusions}

Highly porous materials in $\mathrm{Sr}_{0.96} \mathrm{Y}_{0.04} \mathrm{Ti}_{1-\mathrm{x}} \mathrm{Cr}_{\mathrm{x}} \mathrm{O}_{3}$ system were synthesised and next tested for structural and electrical properties and ability to participate in oxidation/reduction reactions. The results of the study confirmed that chromium incorporated into Y-doped $\mathrm{SrTiO}_{3}$ takes different oxidation states; thus, chromium should be considered simultaneously a donor or acceptor dopant. The mixed electronic-ionic conductivity was observed in $\mathrm{SrTiO}_{3}$ materials double-doped with yttrium and chromium in both-air and in $\mathrm{H}_{2} / \mathrm{Ar}$ atmosphere. Moreover, these studies have shown that the introduction of small amounts of chromium (STO_4Y_2Cror STO_4Y_4Cr) into strontium titanate structure does not improve the redox capability of this system; also the deterioration of the conductivity due to the compensation of various types of defects is significant. These observations lead to the conclusion that only the use of composite material in the function of the anode in SOFC technology will ensure both, the high conductivity and the high catalytic activity of this material. As indicated by the results discussed in this work, it is rather not possible in the case of single-phase material since the improvement of electrical parameters leads to worsening of other properties.

Funding information This work was financially supported by the National Science Centre of the Republic of Poland, Grant No. 2014/14/ E/ST5/00763

Open Access This article is distributed under the terms of the Creative Commons Attribution 4.0 International License (http:// creativecommons.org/licenses/by/4.0/), which permits unrestricted use, distribution, and reproduction in any medium, provided you give appropriate credit to the original author(s) and the source, provide a link to the Creative Commons license, and indicate if changes were made.

\section{References}

1. Drożdż E, Łańcucki Ł, Łącz A (2016) Synthesis, microstructural properties and chemical stability of $3 \mathrm{DOM}$ structures of $\mathrm{Sr}_{1}$ ${ }_{-\mathrm{x}} \mathrm{Y}_{\mathrm{x}} \mathrm{TiO}_{3}$. J Therm Anal Calorim 125(3):1225-1231

2. Puengjinda P, Muroyama H, Matsui T, Eguchi K (2012) Optimization of anode material composed of Y-doped $\mathrm{SrTiO}_{3}$ and metal and/or oxide additives for solid oxide fuel cells. J Power Sources 204:67-73

3. Sudireddy BR, Blennowc P, Nielsen KA (2012) Microstructural and electrical characterization of $\mathrm{Nb}$-doped $\mathrm{SrTiO}_{3}$-YSZ composites for solid oxide cell electrodes. Solid State Ionics 216:44-49

4. Drożdż E, Łącz A, Koleżyński A, Mikuła A, Mars K (2017) Experimental and theoretical studies of structural and electrical properties of highly porous $\mathrm{Sr}_{1-\mathrm{x}} \mathrm{Y}_{\mathrm{x}} \mathrm{TiO}_{3}$. Solid State Ionics 302: 173-179

5. de Souza RA (2015) Oxygen diffusion in $\mathrm{SrTiO}_{3}$ and related perovskite oxides. Adv Funct Mater 25(40):6326-6342
6. Li X, Zhao H, Zhou X, Xua N, Xiea Z, Chen N (2010) Electrical conductivity and structural stability of La-doped $\mathrm{SrTiO}_{3}$ with A-site deficiency as anode materials for solid oxide fuel cells. Int J Hydrog Energy 35(15):7913-7918

7. Uematsu K, Sakurai O, Mizutani N, Kato M (1984) Electrical properties of La-doped $\mathrm{SrTiO}_{3}$ (La: 0.1 to 2.0 at\%) single crystals grown by xenon-arc image floating zone method. J Mater Sci 19(11): 3671-3679

8. Buscaglia MT, Maglia F, Anselmi-Tamburini U, Marré D, Pallecchi I, Ianculescu A, Canu G, Viviani M, Fabrizio M, Buscaglia V (2014) Effect of nanostructure on the thermal conductivity of Ladoped $\mathrm{SrTiO}_{3}$ ceramics. J Eur Ceram Soc 34(2):307-316

9. Torabi A, Etsell TH (2013) Electrochemical behavior of solid oxide fuel cell anodes based on infiltration of Y-doped $\mathrm{SrTiO}_{3}$. J Power Sources 225:51-59

10. Vasechko V, Huang B, Ma Q, Tietz F, Malzbender J (2014) Thermomechanical properties of Y-substituted $\mathrm{SrTiO}_{3}$ used as reoxidation stable anode substrate material. J Eur Ceram Soc 34(15): 3749-3754

11. Fongkaew I, Thienprasert JT, Limpijumnong S (2017) Identification of $\mathrm{Mn}$ site in $\mathrm{Mn}$-doped $\mathrm{SrTiO}_{3}$ : First principles study. Ceram Int 43:381-385

12. Horikiri F, Han LQ, Kaimai A, Otake T, Yashiro K, Kawada T, Mizusaki J (2006) The influence of grain boundary on the conductivity of donor doped $\mathrm{SrTiO}_{3}$. Solid State Ionics 177(26-32):2555-2559

13. Blennow P, Hansen KK, Wallenberg LR, Mogensen M (2009) Electrochemical characterization and redox behavior of $\mathrm{Nb}$-doped $\mathrm{SrTiO}_{3}$. Solid State Ionics 180(1):63-70

14. Łącz A, Łańcucki Ł, Lach R, Kamecki B, Drożdż E (2018) Structural and electrical properties of Cr-doped $\mathrm{SrTiO}_{3}$ porous materials. Int J Hydrog Energy 43(18):8999-9005

15. Harrigan WL, Michaud SE, Lehuta KA, Kittilstved KR (2016) Tunable electronic structure and surface defects in chromiumdoped colloidal $\mathrm{SrTiO}_{3}$-delta nanocrystals. Chem Mater 28(2): 430-433

16. Wang D, Ye J, Kako T, Kimura T (2006) Photophysical and photocatalytic properties of $\mathrm{SrTiO}_{3}$ doped with $\mathrm{Cr}$ cations on different sites. J Phys Chem B 110(32):15824-15830

17. Sulaeman U, Yin S, Sato T (2011) Solvothermal synthesis and photocatalytic properties of chromium-doped $\mathrm{SrTiO}_{3}$ nanoparticles. Appl Catal B Environ 105(1-2):206-210

18. Andreasson BP, Janousch M, Staub U, Meijer GI, Delley B (2007) Resistive switching in Cr-doped $\mathrm{SrTiO}_{3}$ : an X-ray absorption spectroscopy study. Mater Sci Eng B 144(1-3):60-63

19. Lu LW, Ni S, Liu G, Xu XX (2017) Structural dependence of photocatalytic hydrogen production over $\mathrm{La} / \mathrm{Cr}$ co-doped perovskite compound $\mathrm{ATiO}(3)(\mathrm{A}=\mathrm{Ca}, \mathrm{Sr}$ and $\mathrm{Ba})$. Int J Hydrog Energy 42(37):23539-23547

20. Abrantes JCC, Labrincha JA, Frade JR (1999) Evaluation of $\mathrm{SrTi}_{1}$ ${ }_{\mathrm{y}} \mathrm{Nb}_{\mathrm{y}} \mathrm{O}_{3+\text { delta }}$ materials for gas sensors. Sens Actuator B Chem 56(3): 198-205

21. Mclntosh S, Gorte RJ (2004) Direct hydrocarbon solid oxide fuel cells. Chem Rev 104(10):4845-4866

22. Shannon RD (1976) Revised effective ionic-radii and systematic studies of interatomic distances in halides and chalcogenides. Acta Crystallogr A 32(5):751-767

23. Balaya P, Jamnik J, Fleig J, Maier J (2007) Mesoscopic hole conduction in nanocrystalline $\mathrm{SrTiO}_{3}$ - A detailed analysis by impedance spectroscopy. J Electrochem Soc 154:69-76

24. Holt A, Kofstad P (1994) Electrical-conductivity and defect structure of $\mathrm{Cr}_{2} \mathrm{O}_{3}$. 2. Reduced temperatures (less-than-similar-to-1000degrees-C). Solid State Ionics 69(2):137-143 
25. Janotti A, Varley JB, Choi M, Van der Walle CG (2014) Vacancies and small polarons in $\mathrm{SrTiO}_{3}$. Phys Rev B 90(8):085202

26. Yáng Z, Harvey AS, Infortuna A, Schoonman J, Gauckler LJ (2011) Electrical conductivity and defect chemistry of $\mathrm{Ba}(\mathrm{x}) \mathrm{Sr}(1-$ $\mathrm{x}) \mathrm{CoyFe}(1-\mathrm{y}) \mathrm{O}(3-$ delta) perovskites. J Solid State Electrochem 15(2):277-284

27. Mashkina E, Magerl A, Ollivier J, Göbbels M, Seifert F (2006) Oxygen mobility in the perovskite $\mathrm{SrTi}_{1}-{ }_{\mathrm{x}} \mathrm{Fe}_{\mathrm{x}} \mathrm{O}_{3}-\delta(\mathrm{x}=0.8)$. Phys Rev B 74(21):214106

28. Slouka C, Holzlechner G, Andrejs L, Navickas E, Hutter H, Fleig J (2015) Oxygen ion conduction in bulk and grain boundaries of nominally donor-doped lead zirconate titanate (PZT): a combined impedance and tracer diffusion study. J Am Ceram Soc 98(10): 3259-3269

29. Liu B, Cooper VR, Xu H, Xiao H, Zhang Y, Weber WJ (2014) Composition dependent intrinsic defect structures in $\mathrm{SrTiO}_{3}$. Phys Chem Chem Phys 16(29):15590-15596

30. Wang X, Hu Q, Zang G, Zhang C, Li L (2017) Structural and electrical characteristics of $\mathrm{Sr} / \mathrm{Ti}$ nonstoichiometric $\mathrm{SrTiO}_{3}$ ceramics. Solid State Commun 266:1-5

Publisher's note Springer Nature remains neutral with regard to jurisdictional claims in published maps and institutional affiliations. 